\title{
LECIONAR LÍNGUAS ESTRANGEIRAS PARA ALUNOS SURDOS: DESAFIOS E OPORTUNIDADES
}

TEACHING FOREIGN LANGUAGES TO DEAF STUDENTS: CHALLENGES AND OPPORTUNITIES

\author{
ENSEÑAR LENGUAS EXTRANJERAS PARA ALUMNOS SORDOS: DESAFÍOS \\ Y OPORTUNIDADES
}

Elita de Medeiros*

\section{Resumo}

Embora as políticas públicas preconizem educação para todos, com igualdade, a prática docente mostra que ainda há um espaço de debates sobre ações necessárias para que se possa alcançar uma educação realmente igualitária e inclusiva para indivíduos surdos. $\mathrm{O}$ objetivo deste artigo é apontar algumas das dificuldades encontradas no ensino de Língua Estrangeira (LE) para surdos em espaços escolares inclusivos. A partir do que indica a legislação e da exposição de algumas das particularidades que distinguem línguas sonoras e línguas viso-espaciais, buscou-se verificar a viabilidade do ensino de LE para surdos. Os resultados desta pesquisa indicam ser possível esse aprendizado, desde que respeitadas as particularidades dos indivíduos surdos.

Palavras-chave: Inclusão. Língua estrangeira. Educação de surdos.

\section{Introdução}

Políticas públicas de inclusão têm feito parte da agenda de muitos países, nas últimas décadas. A Declaração de Salamanca (1994), resolução das Nações Unidas que apresenta princípios, políticas e práticas em educação especial, foi um marco para o início da implementação de políticas de educação inclusiva no Brasil. O texto da Declaração de Salamanca afirma que toda criança "tem direito fundamental à educação, e deve ser dada a oportunidade de atingir e manter o nível adequado de aprendizagem", lembrando que cada criança apresenta "características, interesses, habilidades e necessidades de aprendizagem que são únicas" (1994, p.1). Neste trabalho focamos, principalmente, os alunos surdos e,

\footnotetext{
* Mestranda em Educação pela UNISUL, Pós-graduada em Libras pela Universidade Leonardo da Vince, graduada em Letras/Espanhol pela Universidade Federal de Santa Catarina-UFSC. Revisora e tradutora na Universidade do Sul de Santa Catarina, UNISUL. E-mail: elita.med@gmail.com.
} 
corroborando as afirmações de especialistas da área, consideramos a surdez como uma "diferença” e não como "deficiência".

Por mais que as escolas busquem oferecer educação com igualdade para todos, a prática docente mostra que ainda há muito para debater e discutir sobre o que é possível e necessário realizar para a educação com igualdade de indivíduos com deficiência auditiva. A partir dessas reflexões iniciais, levantou-se a questão que conduziu à pesquisa: frente às obrigações curriculares impostas às escolas, é possível ensinar uma língua estrangeira (LE) para alunos com deficiência auditiva? O objetivo deste trabalho, portanto, é avaliar os desafios e as possibilidades de ensinar línguas estrangeiras para alunos surdos em espaços escolares inclusivos. Para alcançar tal objetivo, partimos do que preconiza a legislação e, ainda, buscamos verificar a viabilidade e a aplicabilidade desse aprendizado. Esta pesquisa caracteriza-se como bibliográfica e também exploratória, por "proporcionar maior familiaridade com o problema, com vistas a torná-lo mais explícito" (GIL, 2010, p. 27).

\section{O que preconiza a legislação}

A Lei 9394/96, que estabelece as diretrizes e bases da educação nacional (LDBEN) dedica um capítulo à Educação Especial. O documento preconiza que a Educação Especial é uma "modalidade de educação escolar oferecida preferencialmente na rede regular de ensino, para educandos com deficiência, transtornos globais do desenvolvimento" (BRASIL, 1996). A mesma lei, nos primeiros parágrafos do capítulo dedicado à Educação Especial, prevê que

$\S 1^{\circ}$ Haverá, quando necessário, serviços de apoio especializado, na escola regular, para atender às peculiaridades da clientela de educação especial.

$\S 2^{\circ} \mathrm{O}$ atendimento educacional será feito em classes, escolas ou serviços especializados, sempre que, em função das condições específicas dos alunos, não for possível a sua integração nas classes comuns de ensino regular (BRASIL, 1996).

Dessa forma, de acordo com a mesma Lei, aos que apresentam necessidades especiais, ou seja, "educandos com deficiência, transtornos globais do desenvolvimento e altas habilidades ou superdotação" (BRASIL, 1996), fica assegurado:

I - currículos, métodos, técnicas, recursos educativos e organização específicos, para atender às suas necessidades; 
II - terminalidade específica para aqueles que não puderem atingir o nível exigido para a conclusão do ensino fundamental, em virtude de suas deficiências [...] (BRASIL, 1996).

Embora a pesquisa de Amorim (2012) não se refira a estudantes com deficiência, seu estudo aponta que, no Brasil, a maioria dos alunos não atinge fluência em LE apenas com seus estudos na Educação Básica, e que somente 5\% desses estudantes consegue obter fluência em inglês. Assim, acreditamos que para os alunos com deficiência auditiva a dificuldade com a LE seja ainda maior, mesmo que não tenhamos encontrado pesquisas que apontem resultados sobre o aprendizado e uso de LE por surdos. Isto aponta para a necessidade de novas reflexões sobre o ensino de LE para esses alunos. As Diretrizes nacionais para a educação especial na educação básica, que abordam a necessidade de estratégias específicas para o ensino de alunos com necessidades educacionais específicas, observam que esses requerem da escola, "uma série de recursos e apoios de caráter mais especializado, que proporcionem ao aluno meios para acesso ao currículo" (BRASIL, 2001, p. 33). Recomendam ainda que seja ampliado o conceito daquilo que se considera "necessidades especiais":

[...] em vez de focalizar a deficiência da pessoa, enfatiza o ensino e a escola, bem como as formas e condições de aprendizagem; em vez de procurar, no aluno, a origem de um problema, define-se pelo tipo de resposta educativa e de recursos e apoios que a escola deve proporcionarlhe para que obtenha sucesso escolar; por fim, em vez de pressupor que o aluno deva ajustar-se a padrões de "normalidade" para aprender, aponta para a escola o desafio de ajustar-se para atender à diversidade de seus alunos (BRASIL, 2001, p. 33).

Embora o documento trate das diretrizes para a Educação Especial, o faz de forma generalizada, pois não aborda disciplinas ou características específicas, informando apenas que "o currículo a ser desenvolvido é o das diretrizes curriculares nacionais para as diferentes etapas e modalidades de Educação Básica" (BRASIL, 2001, p. 57). Também informa que a construção curricular é “aquela garantida na própria LDBEN, complementada, quando necessário, com atividades que possibilitem ao aluno com necessidades educacionais especiais ter acesso ao ensino, à cultura, ao exercício da cidadania e à inserção social produtiva" (BRASIL, 2001, p. 57).

Voltando o olhar para os Parâmetros Curriculares Nacionais: ensino médio e tomando sua última etapa como exemplo (Parte II - Linguagens, Códigos e suas Tecnologias), podemos observar que, embora datado do ano 2000, o texto já acenava para 
uma Base Nacional Comum, que pudesse conter em si "a dimensão de preparação para o prosseguimento de estudos e [...] caminhar no sentido de que a construção de competências e habilidades básicas", alertando ainda para que "o acúmulo de esquemas resolutivos préestabelecidos" pudesse se tornar "o objetivo do processo de aprendizagem" (BRASIL, 2000, p. 16). O mesmo documento, ao tratar da linguagem, define-a como:

[...] capacidade humana de articular significados coletivos em sistemas arbitrários de representação, que são compartilhados e que variam de acordo com as necessidades e experiências da vida em sociedade. A principal razão de qualquer ato de linguagem é a produção de sentido (BRASIL, 2000, p. 19).

Ao se referirem à necessidade do ensino de língua estrangeira nas escolas, os Parâmetros Curriculares da Educação Básica entendem "o domínio de língua(s) estrangeira(s) como forma de ampliação de possibilidades de acesso a outras pessoas e a outras culturas e informações" (BRASIL, 2000, p. 19). O mesmo documento ainda preconiza que "o convívio social requer o domínio das linguagens como instrumentos de comunicação e negociação de sentidos" (BRASIL, 2000, p. 20).

Por outro lado, nos Parâmetros Curriculares Nacionais para o Ensino Médio, observa-se a prescrição da inclusão, nos currículos, de "uma língua estrangeira moderna, como disciplina obrigatória, escolhida pela comunidade escolar, e uma segunda, em caráter optativo, dentro das disponibilidades da instituição" (BRASIL 2000, p. 33). Deve haver, portanto, o ensino de duas línguas estrangeiras, uma obrigatória e outra optativa. No que diz respeito à terminalidade específica, as Diretrizes Nacionais para a Educação Especial na Educação Básica preconizam que:

Quando os alunos com necessidades educacionais especiais, ainda que com
apoios e adaptações necessários, não alcançarem os resultados de escolarização
previstos no Artigo 32 I da LDBEN: "o desenvolvimento da capacidade de
aprender, tendo como meios básicos o domínio da leitura, da escrita e do
cálculo" - e uma vez esgotadas as possibilidades apontadas nos Artigos 24,26 e
32da LDBEN - as escolas devem fornecer-lhes uma certificação de conclusão de
escolaridade denominada terminalidade específica (BRASIL, 2001, p. 59).

O Art. 24 da LDBEN aponta a possibilidade de classificação por promoção, baseada em aproveitamento, em avaliação que independa de etapa anterior, progressão parcial, desde que preservada a sequência curricular, organização de turmas distintas para o ensino de línguas estrangeiras, artes e outras disciplinas. O mesmo artigo ainda prevê que a avaliação será contínua e cumulativa, com prevalência de aspectos qualitativos sobre 
quantitativos, possibilidade de aceleração para alunos com atraso, avanços mediante verificação, aproveitamento de estudos concluídos com êxito, e obrigatoriedade de recuperação preferencialmente paralela. Mais adiante, no texto da LDBEN, estão os únicos aspectos sobre aprendizagem, que são:

I - o desenvolvimento da capacidade de aprender, tendo como meios básicos o pleno domínio da leitura, da escrita e do cálculo; II - a compreensão do ambiente natural e social, do sistema político, da tecnologia, das artes e dos valores em que se fundamenta a sociedade; III - o desenvolvimento da capacidade de aprendizagem, tendo em vista a aquisição de conhecimentos e habilidades e a formação de atitudes e valores; IV - o fortalecimento dos vínculos de família, dos laços de solidariedade humana e de tolerância recíproca em que se assenta a vida social (BRASIL, 1996).

A partir dessas considerações iniciais sobre a legislação, passamos a buscar respostas à questão que norteia esta pesquisa: é possível ensinar uma língua estrangeira para alunos surdos?

\section{Breve reflexão sobre o aprendizado de línguas e a audição}

Conforme exposto anteriormente, infere-se que, em uma educação igualitária, que possa alcançar a todos, e na qual se pressupõe a inclusão, os professores devem fazer o possível para que seus alunos atinjam bom grau de aprendizagem, especialmente em espaços compartilhados com estudantes que apresentem alguma forma de limitação. Neste trabalho, buscamos refletir especificamente sobre alunos com algum nível de surdez.

Quadro 1 - Grau de intensidade de perda auditiva

\begin{tabular}{|l|l|l|}
\hline Denominação & $\begin{array}{l}\text { Medida } \\
\text { em Db }\end{array}$ & Exemplo de comprometimento (a pessoa pode apresentar) \\
\hline $\begin{array}{l}\text { Audição } \\
\text { Normal }\end{array}$ & 0 a 15 & - \\
\hline Surdez leve & 16 a 40 & $\begin{array}{l}\text { Dificuldade para ouvir o som do relógio, ou uma conversação } \\
\text { silenciosa (cochicho). }\end{array}$ \\
\hline $\begin{array}{l}\text { Surdez } \\
\text { moderada }\end{array}$ & 41 a 55 & $\begin{array}{l}\text { Alguma dificuldade para ouvir uma voz fraca ou o canto de um } \\
\text { pássaro. }\end{array}$ \\
\hline $\begin{array}{l}\text { Surdez } \\
\text { acentuada }\end{array}$ & 56 a 70 & Alguma dificuldade para ouvir uma conversação normal. \\
\hline Surdez severa & 71 a 90 & $\begin{array}{l}\text { Dificuldades para ouvir o telefone tocando ou ruídos das máquinas de } \\
\text { escrever num escritório. }\end{array}$ \\
\hline $\begin{array}{l}\text { Surdez } \\
\text { profunda }\end{array}$ & $\begin{array}{l}\text { Acima } \\
\text { de } 91\end{array}$ & $\begin{array}{l}\text { Dificuldade para ouvir o ruído de caminhão, de uma máquina de serrar } \\
\text { madeira, ou o ruído de um avião decolando. }\end{array}$ \\
\hline
\end{tabular}

Fonte: Saberes e práticas da inclusão (BRASIL, 2006, p. 16-17). 
O Quadro 1 foi desenvolvido com base nos dados divulgados pelo Ministério da Educação, na obra Saberes e práticas da inclusão: desenvolvendo competências para o atendimento às necessidades educacionais especiais de alunos surdos (2006). Ao avaliar essas informações, é possível compreender as dificuldades enfrentadas no cotidiano por alunos com diferentes níveis de perda auditiva e o quanto essa circunstância impactará a percepção sonora das línguas de modalidade oral auditiva.

Para crianças ouvintes, a base do aprendizado da língua materna é a audição, visto que, mesmo não sendo o aspecto sonoro o único parâmetro, esse irá se mostrar bastante significativo: crianças ouvem as pessoas com quem convivem e imitam suas características de comunicação, o que pode ser percebido no nível vocabular e na inflexão.

Bandura e Walters (1963) afirmam que a aprendizagem ocorre pela interação com o meio ambiente, através da observação. McLeod (2016, p.1) chama de "modelos" os indivíduos observados por crianças, pois elas "prestam atenção a algumas dessas pessoas (modelos) e codificam seu comportamento. Mais tarde, elas podem imitar (ou seja, copiar) o comportamento que observaram”.

As línguas de sinais são de modalidade viso-espacial e, segundo Dizeu e Caporali (2005, p. 544), configuram a "língua natural dos surdos, pois essa a criança surda adquire de forma espontânea sem que seja preciso um treinamento específico". Sobre a Libras, a Lei 10.436 de 24 de abril de 2002, no parágrafo único do Art. $1^{\circ}$, assim define a Língua Brasileira de Sinais :

Entende-se como Língua Brasileira de Sinais - LIBRAS a forma de comunicação e expressão, em que o sistema linguístico de natureza visualmotora, com estrutura gramatical própria, constitui um sistema linguístico de transmissão de ideias e fatos, oriundos de comunidades de pessoas surdas do Brasil (BRASIL, 2002).

Dizeu e Caporali (2005, p. 584), contudo, alertam que a oficialização da Libras, “começa a abrir novos caminhos, sem, no entanto, deixar de gerar polêmicas por profissionais que trabalham com surdos e por surdos oralizados, que não se sentem parte de uma comunidade surda e não veem mérito nessa vitória para a comunidade surda".

A comunidade surda tem sua própria cultura, no entanto, é necessário considerar que os indivíduos surdos têm freqüentes contatos com ouvintes. O Art. 208 da Constituição Federal recomenda "atendimento educacional especializado aos portadores de deficiência, preferencialmente na rede regular de ensino" (BRASIL, 2016). Essa recomendação traz 
aos profissionais da Educação um alerta sobre a necessidade de reconhecimento das particularidades dos indivíduos surdos, de maior respeito a sua cultura e a sua língua, a Libras. Dizeu e Caporali (2005, p. 594) observam que, lamentavelmente, "na maioria das vezes, o surdo só é visto pela sua incapacidade, sendo depreciada sua diversidade cultural e linguística".

Assim como a Libras constitui um sistema de comunicação diferente da língua portuguesa, outras línguas estrangeiras, utilizadas por indivíduos surdos, também apresentam sistemas linguísticos particulares de sinais, como a American Sign Language (ASL), utilizada pelos surdos norte-americanos, ou a Langue des Signes Française (LSF), usada pelos franceses, apenas para citar dois exemplos. De forma semelhante à Libras, a ASL e a LSF apresentam sistemas próprios e arbitrários de transcrição que permitem a leitura aos seus usuários.

Ao refletirmos sobre a possibilidade de ensinar uma língua estrangeira, baseada em sons, a quem não utiliza uma língua sonora, surgem algumas questões: Que procedimentos devem ser seguidos para a certificação? Deve-se aplicar a terminalidade específica? Que nota deve se atribuir ao indivíduo para efeitos de currículo? O mínimo para aprovação? Essas são perguntas para as quais a maioria dos professores de línguas estrangeiras que trabalham com alunos surdos procuram respostas. A legislação sobre o ensino de Língua Estrangeira não trata especificamente dos casos de indivíduos surdos ou com perda auditiva, embora as línguas faladas sejam baseadas, principalmente, em sons, tanto que dois campos da linguística são a Fonética e a Fonologia.

A Fonética estuda os sons como entidades físico-articulatórias isoladas (aparelho fonador), descreve os sons da linguagem e analisa suas particularidades acústicas e perceptivas. Fundamenta-se no estudo dos sons da voz humana, examinando suas propriedades físicas, independentemente do papel linguístico, ao construir as formas da língua (CALLOU; LEITE, 1995). De acordo com Saussure (2002, p. 43), a Fonética “é uma ciência histórica; analisa acontecimentos, transformações e se move no tempo. A fonologia se coloca fora do tempo, já que o mecanismo da articulação permanece sempre igual a si mesmo".

A Fonologia estuda as diferenças fônicas intencionais, distintivas, isto é, que se unem a diferenças de significação; estabelece a relação entre os elementos de diferenciação e quais as condições em que se combinam uns com os outros para formar morfemas, palavras e frases. A Fonética se diferencia da Fonologia por considerar os sons 
independentes das oposições paradigmáticas e combinações sintagmáticas (CALLOU; LEITE, 1995).

Karnop (2005) observa que há uma Fonologia das línguas de sinais, ressaltando que, mesmo com as diferenças existentes entre as línguas orais e as de sinais, o termo Fonologia também é usado para se referir ao estudo de elementos básicos de línguas de sinais. Em Sign language structure, Stokoe (1978) propõe os termos "quirema" e "quirologia", pensando assim evitar que fossem subestimadas as diferenças entre os dois sistemas linguísticos. O quirema refere-se às unidades formacionais dos sinais e compreende: configuração de mão, localização e movimento. A quirologia se relaciona ao estudo das combinações. Karnop (2005, p. 30) observa que, outros pesquisadores das línguas de sinais,

[...] incluindo Stokoe em edição posterior (1978), têm utilizado os termos 'Fonema' e 'Fonologia'. O argumento para a utilização desses termos é o de que as línguas de sinais são línguas naturais que compartilham princípios lingüísticos [sic] subjacentes com as línguas orais, apesar das diferenças de superfície entre fala e sinal.

Ao se observar a legislação, percebe-se que a LDBEN assegura "aos educandos com deficiência, transtornos globais do desenvolvimento [...] currículos, métodos, técnicas, recursos educativos e organização específicos, para atender às suas necessidades" (BRASIL, 1996). Os Parâmetros Curriculares da Educação Básica preconizam uma "Base Nacional Comum" (BRASIL, 2000, p. 16), também para os indivíduos com necessidades educacionais especiais. As Diretrizes Nacionais para a Educação Especial na Educação Básica informam que a construção curricular é "aquela garantida na própria LDBEN" (BRASIL, 2001, p. 57). O mesmo documento preconiza que "o aluno que apresenta necessidades educacionais especiais" tenha "acesso ao ensino, à cultura, ao exercício da cidadania e à inserção social produtiva" (BRASIL, 2001, p. 57).

Diante dos direitos propostos pelos textos governamentais, surgem algumas questões: Que espécie de resposta educativa, recursos e apoios são possíveis ou necessários para o ensino de LE para surdos? De que forma uma língua estrangeira, no caso de alunos surdos, permite sua "inserção social", principalmente produtiva? Acreditamos na importância de uma organização específica de métodos, técnicas e recursos educativos, para atender as necessidades dos surdos e da necessidade de se considerar sua cultura e língua próprias,suas particularidades, na introdução deste trabalho.

Nosso convite à reflexão sobre as reais possibilidades de ensino, aprendizagem e aplicabilidade de LE para surdos passa, portanto, pela sugestão de uma adaptação dos 
objetivos da disciplina. $\mathrm{O}$ aluno surdo poderia desenvolver habilidades de escrita, leitura e tradução. Acreditamos na possibilidade desse ensino, mas certamente são necessárias novas pesquisas para verificar quais recursos e apoios seriam necessários. Dessa forma, para nossa pergunta de pesquisa, que questiona se seria possível ensinar uma língua estrangeira para indivíduos surdos, a resposta é afirmativa, desde que o enfoque seja voltado às habilidades de leitura, escrita e tradução.

Por outro lado, a legislação precisa ser mais específica em relação ao ensino de línguas estrangeiras, para que seja possível atender de forma mais justa os indivíduos com necessidades especiais de aprendizagem, por meio de adaptação curricular e metodológica específicas para suas necessidades. Novas pesquisas acerca do ensino e da aprendizagem de língua estrangeira por indivíduos surdos ou com deficiência auditiva devem ser estimuladas, considerando-se que o domínio de línguas estrangeiras dá acesso a outras culturas, possibilita a interação com outros indivíduos, mesmo que apenas por meio da escrita.

\section{Considerações finais}

Nesta pesquisa bibliográfica e exploratória, estudando a legislação e publicações sobre o tema, buscamos verificar a viabilidade e aplicabilidade do aprendizado de língua estrangeira por alunos surdos, levando em conta que, nessas disciplinas, as práticas docentes configuram verdadeiros desafios. Embora a LDBEN 9394/96 dedique um capítulo à educação especial, mencionando apoio especializado para atender peculiaridades da clientela para esta modalidade de educação, encontramos dificuldades no que se refere ao ensino de língua estrangeira (LE).

Amorim (2012) observa que apenas 5\% dos alunos brasileiros atingem fluência em inglês, apontando a enorme dificuldade que têm os estudantes brasileiros para utilizar línguas estrangeiras com competência. Se até mesmo a parcela de alunos ouvintes que atingem fluência é pequena, podemos, a partir do percentual alcançado por Amorim, vislumbrar as dificuldades enfrentadas por alunos surdos no aprendizado de LE .

A adaptação sugerida pela legislação é necessária e o enfoque deve ser na leitura, escrita e tradução. Desta forma, a "resposta educativa" esperada dos alunos seria mais coerente, além de possibilitar um ensino significativo, com possibilidade de o surdo alcançar diferentes culturas, pelo domínio de uma LE. Assim, notas e currículo teriam sua 
base nos ganhos de aprendizagem efetivos desses alunos, e não no ensino de uma língua sonora a quem faz uso de língua viso-espacial.

A legislação, no entanto, aponta para uma educação que não considera a cultura e a língua dos surdos, a despeito do reconhecimento da Libras como língua oficial da comunidade surda. Mesmo que a legislação preconize "adaptações necessárias", encontramos dificuldades para essa prática no que se refere ao ensino de LE para surdos. As diferenças entre as línguas orais e viso-espaciais estão na base das dificuldades enfrentadas pelos surdos quando se dispõem a estudar uma língua oral.

No ano 2000, os Parâmetros Curriculares da Educação Básica acenaram para uma Base Nacional Comum, pontuando o domínio de LE como agente da ampliação de possibilidades de acesso a diferentes pessoas e culturas. A preparação de professores de LE, contudo, não inclui as línguas de sinais dessas LE, como por exemplo a American Sign Language (ASL). Consideramos pertinente salientar que, se a Libras fosse de ensino obrigatório a todos, desde os primeiros anos de escolarização, a inclusão dos surdos se daria de forma satisfatória, possibilitando sua interação com colegas, professores e a comunidade ouvinte. Ter a Libras como segunda língua obrigatória em todas as escolas e em todos os níveis sinalizaria para o verdadeiro reconhecimento da comunidade surda, com sua cultura e língua próprias, facilitando o reconhecimento da identidade do indivíduo surdo por ele mesmo e pela comunidade de ouvintes, que é numericamente maior no mundo que o cerca.

\begin{abstract}
Although public policies advocate equal education for all, teaching practice shows that there is still room for debate on what actions are necessary to achieve a truly egalitarian and inclusive education for deaf individuals. The objective of this article is to point out some of the difficulties encountered in the teaching of Foreign Languages (LE) to the deaf in inclusive school spaces. From what is indicated by the legislation and the presentation of some of the peculiarities that distinguish spoken languages and visual-spatial languages, we sought to verify the feasibility of teaching LE to deaf people. The results of this research indicate that this learning is possible, provided that the particularities of the deaf individuals are respected.
\end{abstract}

Keywords: Inclusion. Foreign language. Deaf education. 


\section{Resumen}

Aunque las políticas públicas destacan que la educación es para todos, respetando la igualdad, la práctica docente muestra que todavía hay un espacio de debates sobre acciones necesarias para alcanzar una educación realmente igualitaria e inclusiva para las personas sordas. El objetivo de este artículo es registrar algunas de las dificultades encontradas en la enseñanza de Lengua Extranjera (LE) para sordos en espacios escolares inclusivos. A partir de lo que indica la legislación y la exposición de algunas de las particularidades que distinguen lenguas sonoras y lenguas viso-espaciales, se buscó verificar la viabilidad de la enseñanza de LE para sordos. Los resultados de esta investigación indican que es posible ese aprendizaje, siempre que se respeten las particularidades de las personas sordas.

Palabras clave: Inclusión. Lengua extranjera. Educación de sordos.

\section{Referências}

AMORIM, M. Brasileiros não sabem falar inglês: apenas 5\% dominam o idioma. O Globo, 30/09/2012. Disponível em: <http://oglobo.globo.com/economia/emprego/brasileiros-naosabem-falar-ingles-apenas-5-dominam-idioma-6239142>. Acesso em: 09 out. 2015.

BANDURA, A. ; WALTERS, R. H.. Aprendizaje social y desarrollo de la personalidade. Mexico City: Cidade Alianza, 1963.

BRASIL. Constituição da República Federativa do Brasil : tex to constitucional promulgado em 5 de outubro de 1988, com as alterações determinadas pelas Emendas Constitucionais de Revisão nos 1 a 6/94, pelas Emendas Constitucionais nos 1/92 a 91/2016 e pelo Decreto Legislativo no 186/2008. - Brasília : Senado Federal, Coordenação de Edições Técnicas, 2016. Disponível em: https://www2.senado.leg.br/bdsf/bitstream/handle/id/518231/CF88_Livro_EC91_2016.pdf Acesso em 17 out. 2018.

BRASIL. Lei $\mathbf{N}^{\circ}$ 9394, de 20 de dezembro de 1996, estabelece as diretrizes e bases da educação nacional . Disponível em: 〈http://www.planalto.gov.br/ccivil_03/leis/19394.htm>. Acesso em: 21 jan. 2015.

BRASIL.Parâmetros Curriculares Nacionais: ensino médio. 2000. Disponível em: http://portal.mec.gov.br/seb/arquivos/pdf/14_24.pdf . Acesso em 22 jan. 2015.

BRASIL.Ministério da Educação. Diretrizes nacionais para a educação especial na educação básica. MEC/SEESP, 2001. Disponível em: http://portal.mec.gov.br/seesp/arquivos/pdf/diretrizes.pdf Acesso em: 10 jan.2015

BRASIL. Lei no 10.436, de 24 de abril de 2002. Dispõe sobre a Língua Brasileira de Sinais - Libras e dá outras providências. Diário Oficial [da] União, Brasília, DF, 25 abr.2002. Disponível em: http://www.planalto.gov.br/ccivil_03/leis/2002/L10436.htm . Acesso em: 10 mai. 2017. 
BRASIL. Saberes e práticas da inclusão: desenvolvendo competências para o atendimento às necessidades educacionais especiais de alunos surdos. [2. ed.] Brasília: MEC, 2006. Disponível em: http://portal.mec.gov.br/par/192-secretarias-112877938/seespesducacao-especial-2091755988/12656-saberes-e-praticas-da-inclusao-ensino-fundamental. Acesso em: 20 dez. 2017.

CALLOU, D.; LEITE, Y.. Iniciação à Fonética e à Fonologia. 5 ed. Rio de Janeiro, Zahar, 1995.

DECLARAÇÃO DE SALAMANCA, 1994. Disponível em: http://portal.mec.gov.br/seesp/arquivos/pdf/salamanca.pdf. Acesso em: 20 jan. 2015.

DIZEU, L. C. T. B.; CAPORALI, S. A. A língua de sinais constituindo o surdo como sujeito. Educação \& Sociedade. Campinas, vol. 26, n. 91, p. 583-597, Maio/Ago. 2005, p. 583-597. Disponível em: http://www.scielo.br/pdf/es/v26n91/a14v2691.pdf. Acesso em 17 out. 2018.

KARNOP, L.. Fonética e fonologia. Universidade Federal de Santa Catarina, 2005. Disponível em:

http://www.Libras.ufsc.br/colecaoLetrasLibras/eixoFormacaoBasica/foneticaEFonologia/a ssets/359/FoneticaFonologia_TextoBase.pdf . Acesso em: 09 out. 2018.

MCLEOD, S.. Bandura - Social Learning Theory. SimplyPsychology. 2016. Disponível em: https://www.simplypsychology.org/bandura.html . Acesso em: 09 out. 2018.

SAUSSURE, F.. Curso de Linguística Geral. 24 ed. São Paulo: Cultrix, 2002.

STOKOE, W. C. Sign language structure. Silver Spring: Linstok Press, 1978. 